Original Contribution

\title{
RELATIONSHIPS BETWEEN EDUCATION AND INNOVATIONS IN THE RECREATION INDUSTRY IN BULGARIA
}

\author{
B. Dimitrova* \\ Faculty of Public Health, Health Care and Tourism, National Sports Academy "V. Levski", \\ Sofia, Bulgaria
}

\begin{abstract}
PURPOSE: The goal of the study is to analyse the advantages in the Bulgarian full educational vertical in wellness culture, in two professional fields and establish the external evaluation for proposed knowledge, intellectual and practical skills of specialised personnel in Bulgarian niche tourism by defining the importance of the studied indicators.

METHODS: We apply a psychometric assessment of customers' opinions to obtain results on the meanings of numbers (points/weight). The respondents' opinions we measure with an adaptive version of the questionnaire for studying through the usage of smart tools of google drive.

RESULTS: This paper offers an analysis of advantages for accredited and integrated into the practice innovations in support of Niche tourism. We created new educational programs in response to the latest changes in the Bulgarian educational and scientific policies and regulations. In the last 10 years, Bulgaria has successfully integrated six new specialized (in niche tourism) programs in two professional categories - Healthcare \& sport and is establishing a Centre for Excellence.

CONCLUSIONS: The established regularities are a valuable reference point to build the full educational vertical from secondary level to doctoral level with innovative programs in support of smart services for Niche tourism and knowledge-based economy in Bulgaria.
\end{abstract}

Key words: Educational innovative Programs, Niche tourism, professional competences, innovative smart model, new job positions.

\section{INTRODUCTION}

The modern recreational sector and niche tourist market are aimed mainly towards clients that live dynamically and need an effective and quick recovery $(1,2)$. To begin with, the clients need deep relaxation, recreation and re-energisation utilising intelligent therapies based on natural product lines and balanced daily regime to have a healthy lifestyle. (3). The number of vacations connected with travelling to a wellness destination (offering health packages) has increased drastically through the period of 2017-2018, but the lack of specialised staff remains a global problem (4). Based on scientific data of the global wellness institute, the lack of qualified staff with specific knowledge and skills in the area of tourism

*Correspondence to: Ass. Prof. Bistra Dimitrova, D.Sc., Faculty of Public Health, Health Care and Tourism, National Sports Academy, Sofia, Bulgaria Email: dimitrova.bistra@yahoo.com equates to around 180,000 people (5). The same study also concluded that there is an urgent need for specialised programs in different educational levels to train staff from operational up until management level. The recreational industry and niche tourism serve more than 4 billion people around the world, which makes the global wellness and spa industry business with a revenue of more than 300 billion euros annually $(6,7)$.

Unfortunately, there is no statistical data about the total revenue of the industry on the Balkans $(8,9)$. The industry has a deep need for new marketing strategies, and management approaches in the wellness and spa business globally $(10,11)$. There is also a need for a new theory for the recreational industry and niche tourism in terms of digitalisation and the incorporation of intelligent services $(12,13)$. Bulgaria has a rich tradition in thermal tourism, and according to different informational sources. The country is ranked 
top 5 in the world for countries with the most vibrant and most diversified mineral waters by varying temperatures, water physics and chemical composition $(14,15)$. Up to this date, the sectors for wellness and spa still do not have a clear vision, structured requirements and standards (16). There is a lack of specialised wellness and spa staff with highquality skills, speaking at least two languages for correct communication skills $(17,18)$.

This paper offers accredited and successfully integrated into the practice innovations in support of the Recreation industry and Niche tourism. Was created educational and certification programs in response to the latest changes in the Bulgarian educational and scientific policies and regulations. From 2007 to 2019, Bulgaria has turned into the European scientific and educational leader by successfully integrating six new specialised (in niche tourism) programs in two professional categories - Healthcare and sport. Through the Erasmus+ (KA2) program, we received a subsidy, and a new European profession was designed- wellness instructor $(19,20)$. In 2018, February a project is won and contract signed for building and developing a centre of Excellence "Heritage BG". The prioritising field was "creative and recreation industries" under the operational program "science and education for intellectual growth", co-financed by the European structural and investment funds for the program period 2014-2020 (21). Thus, Bulgaria is the first country that has accredited and integrated a full educational vertex from middle school to Doctoral level (for wellness, spa and thalasso culture). Simultaneously was built the highest level scientific infrastructure in Europe - the Bulgarian centre for Excellence in Creative and Recreation industry ("Heritage BG") and the specialised scientific body inside of it for Social innovations, Recreation human design, and Niche tourism.

\section{METHODS}

The study has been taken by 210 people ( 23 owners or managers of Wellness\&SPA centers, scholars, Bachelor on Sport, Doctoral students and Master degree graduates in wellness, spa and thalasso culture) all Bulgarians, aged 1736. There were 49 men and 161 women in the study. The median age of the participants in the study was 26,5 . For the study, the targeted group we divided into two age segments instead of educational classes (17-21: 25; 22-
26: 60; 27-31: 87; 32-36: 38 years old); practical experience (less than three years, from four to seven years, and above eight years). The job position levels are: CEO, manager, operational employee / therapist and non-graduates in the wellness and spa area. The examinations amongst the age groups were concluded in the Bulgarian university with accredited and integrated educational programs in wellness culture - in the last days of the summer semesters (National Sports Academy, Sofia: 2016-2019), declarations were signed for agreement for the data of the study to be published. Within the period March to June 2018 and 2019, a psychometric measurement of specialised staff opinions (Graduated, Teaching or Learning students from the specific programs) was conducted in two accredited professional fields: 7.5 Healthcare and 7.6 Sport. The respondents' opinions we measure with an adaptive version of the questionnaire for studying through the usage of smart tools of google drive. For accomplishing the goal of the study, we used: a test for the psychometric grade. The level of the psychometric measurement by the opinions of the respondents is a result of the meaning of the numbers (through the order of specific questions A-fixed question by-X of B-number of questions) used for all questions asked (points). They measure the relation of connected items. We arrange the questions according to the number of items that are prioritised based on their indicator. We receive arranged/ranking for classification of the particular meaning of the relative study significance for the quality of education in the integrated educational programs (University Educational level), as well as the content in the new profession in levels: Bachelor's degree and secondary/professional school. The expectation for the content and design of the created smart app was also studied. This intellectual product was created to assist the staff at the recreation centres in the Bulgarian Niche tourism and also to work as an instrument for certification of the acquired specific professional competencies.

The goal of the study is to analyse the advantages in the Bulgarian full educational vertical in wellness culture, in two professional fields and establish the external evaluation for proposed knowledge, intellectual and practical skills of specialised personel in Bulgarian niche tourism by defining the importance of the studied indicators. 


\section{RESULTS}

For the first time, the Bulgarian educational and scientific accomplishments in the sector of wellness and spa are showcased. In the centre for Excellence in the Creative and Recreation industry ("Heritage BG"), the 40-second laboratory is modelled according to the global science studies based on water healthy influence and accredited Bulgarian educational model for training of specialised staff for wellness culture and Niche tourism. This is going to attract young people in Bulgaria for the European and multinational professional realisation through graduating in the specialised bachelor, masters or doctoral programs in the newly incorporated job positions in the national classification of the professions and job positions (NCPP, 2014): manager or advisor of Spa center (ID: 14316022), of wellness center (ID: 1431-6023), of thalasso center (ID: 1431-6024).

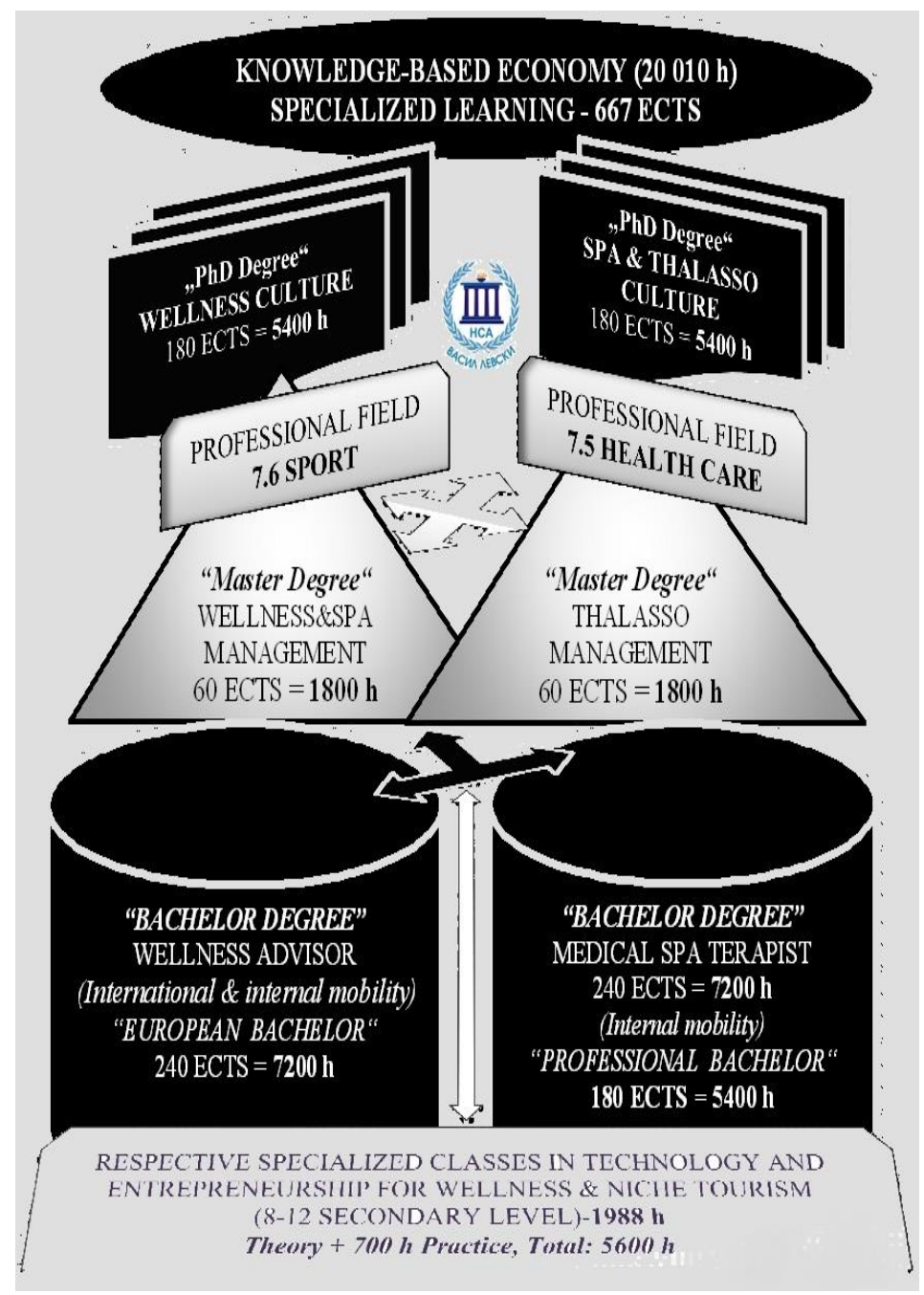

Figure 1. Architectonics of the Bulgarian education \& science model for the Wellness \& Spa \& Thalasso culture.

Presenting the first programs in Europe for Doctoral degree (Wellness - health promotion), the recent published (in July 2019) bachelor program (Wellness adviser) and profiled classes from 8th to 12th grade in Technology and Entrepreneurship in Wellness and Niche tourism (in December 2018). Simultaneously for the first time, it is presented the two working educational verticals for specialised staff in the Bulgarian niche tourism (professional fields: 7.6.Sport and 7.5. Health care). The social mission of the new students is through using volunteers in the two professional majors in NSA "V. Levski" in Wellness, Spa and Thalasso culture as well as the partnership network of the young movement Blue Cluster and Cluster Bridge (initiated by the Bulgarian wellness and spa young specialists and doctoral students) to attract citizens to applying a daily healthy 
lifestyle. The goal is to spread a new culture for the communication with water, attract citizens for responsibility of the water reserve (Mineral and spring) and her effective usage in the Balkans, in Europe and in the world. The organisation of international forums that promote health prevention through social educational and scientific innovations for reaching the knowledge-based economy for the transformation of Bulgaria into the Silicon Valley of water. At the same time, an intellectual, scientific infrastructure will be built in Sofia as well as the transfer of the new science: Aquaphotomics - global innovation of the Bulgarian Prof. Rumiana Tsenkova, D.Sc. For the first time in Bulgarian practice scientific innovation standards, creative business products, intellectual instruments that stimulate new politics and strategies in the major have been developed and implemented. The innovations have motivated a clustered international responsibility about the culture of quality in the education of young people and in the usage of water for health prevention, longevity and treatment. Center for Excellence: Heritage BG is projected to start an inclusive informational campaign for national, regional and international level in support of the citizens through the usage of multiapplication potential of the partner networks of the participants in the educational and scientific international forms - media, citizen sector, business, industry, local and executive power, educational institutions and public figures.

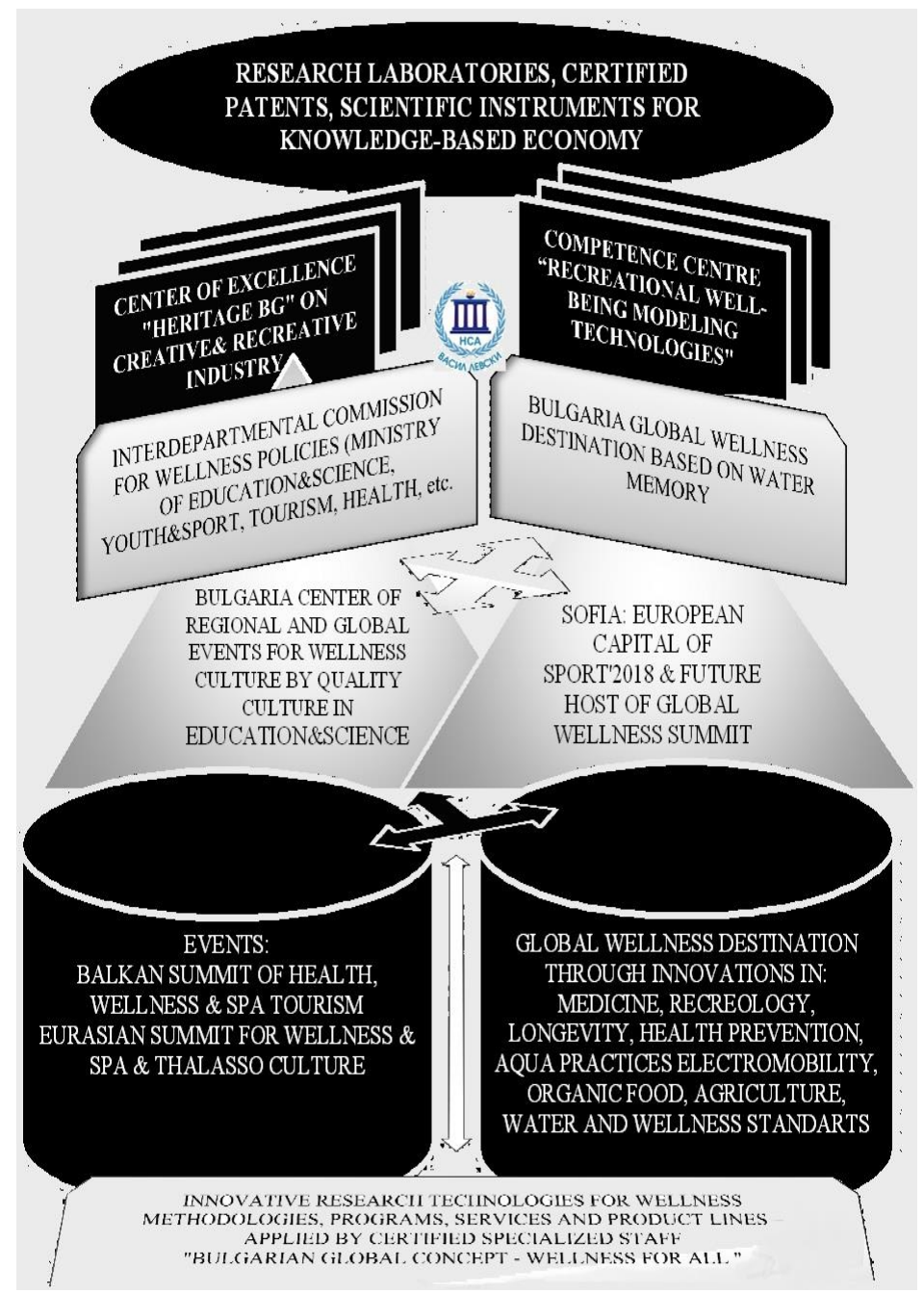

Figure 2. Logistics for the realisation of the accomplished and upcoming Bulgarian scientific innovations and research business models.

Bulgaria launches a new global concept: Wellness for everyone - Healthy lifestyle practices of every citizen on the planet. In response to the program' priorities (2014-2020) for the direction of the creative and recreation industry in the EU Operational program Education and Science for intelligent growth. The young Bulgarian specialists set the 
following specific goals for realisation: 1. To spread the opportunities for the global and professional realisation of young people in the sector of wellness and spa industry through cluster structures of the international youth movement Blue Cluster; 2.

With the help of the online live streaming events, to spread the culture of the quality in "wellness and spa, education - sciences products - services" and to attract the citizens to apply the philosophy of healthy lifestyle Wellness for everyone; 3. To formulate transparent politics at national, regional and, international level for water usage in support of the prevention of health and/or treatment with the help of the unique properties of the Bulgarian mineral waters and their memory in particular.

On Scheme one, we show the integrated Bulgarian educational model in the recreation industry and niche tourism and on Scheme two the logistics for the realisation of the accomplished and upcoming Bulgarian scientific innovations and research business models. For the first time, data about the Bulgarian region and in particular the Bulgarian programs educational and scientific models from high school to doctorate are available. Scheme one summarises the existing programs about education and training in the National sports academy "V. Levski", which are successfully accredited and offered in practice. Scheme two presents the logistics for the realisation of the Bulgarian scientific innovations and research business models This information is accurate and is acquired from the official documentation for accreditation by our position as an author and manager of the presented model and the research \&innovations goals of the action plan in the project for creating and equipping the new Center for Excellence. Bulgaria has other providers of specialised education that have just one program, for example, the Universities in Plovdiv and Varna. The logistics for achieving the vertical upgrade consists of a couple of steps based on acquired European experience and analysis of the changes in the educational politics in the last decade. Some of the best European practices were analysed and transferred based on analysis and conclusion of the international market studies as well as specialised talent in the recreation industry and niche tourism. A ten-year action plan was established based on a detailed analysis of the changes and priorities of the Bulgarian education and science politics. The documentation connected with education and training contains the expert analysis of the changes in the EU\&Bulgarian laws for high school and university education, analysis of the regulations and criteria for accreditation, the structure of programs for professional managers, analysis of the expected key and professional competencies for educating welldeveloped specific knowledge, intellectual and practical skills according to the European regulations and educational qualification frame for each level. The developed documentation connected with the scientific studies and innovations contains the analysis of experts of priorities in program periods according to the European educational and scientific area.

Our experience leads us to develop the new program in the educational and scientific level "Doctoral degree". After the successful accreditation (score 9,2 of 10 points), we systematised a project with equipment of an experimental laboratory for "Social innovations, recreation human design and niche tourism", as a part of the Centre of Excellence "Heritage BG" under the EU Operational Program "Education\&Science for intelligent growth" (OP ESIG: 2014-2020). The contract is successfully signed in February 2018 with the financial support of the European Structural, Social funds and the Bulgarian government (30\%).

According to Ellis (2013), the specific problems in the management of the Wellness industry at the moment are: 1 . The challenges connected with the current and future managers in the Spa and Wellness industry; 2. The requirements for high-level skills acquired during the carrier/path of growth; 3 . Challenges in accepting manager positions which require interdisciplinary skills and knowledge, coupled with the understanding of the culture of health and peoples' motivation for a healthy lifestyle. The showcased logistic in Figure $\mathbf{3}$ aims to show the broader socioeconomic benefits from the EU investments in scientific researches and innovations. An opportunity was pointed out for institutions, individuals or teams to showcase their best practices and accomplishments. 


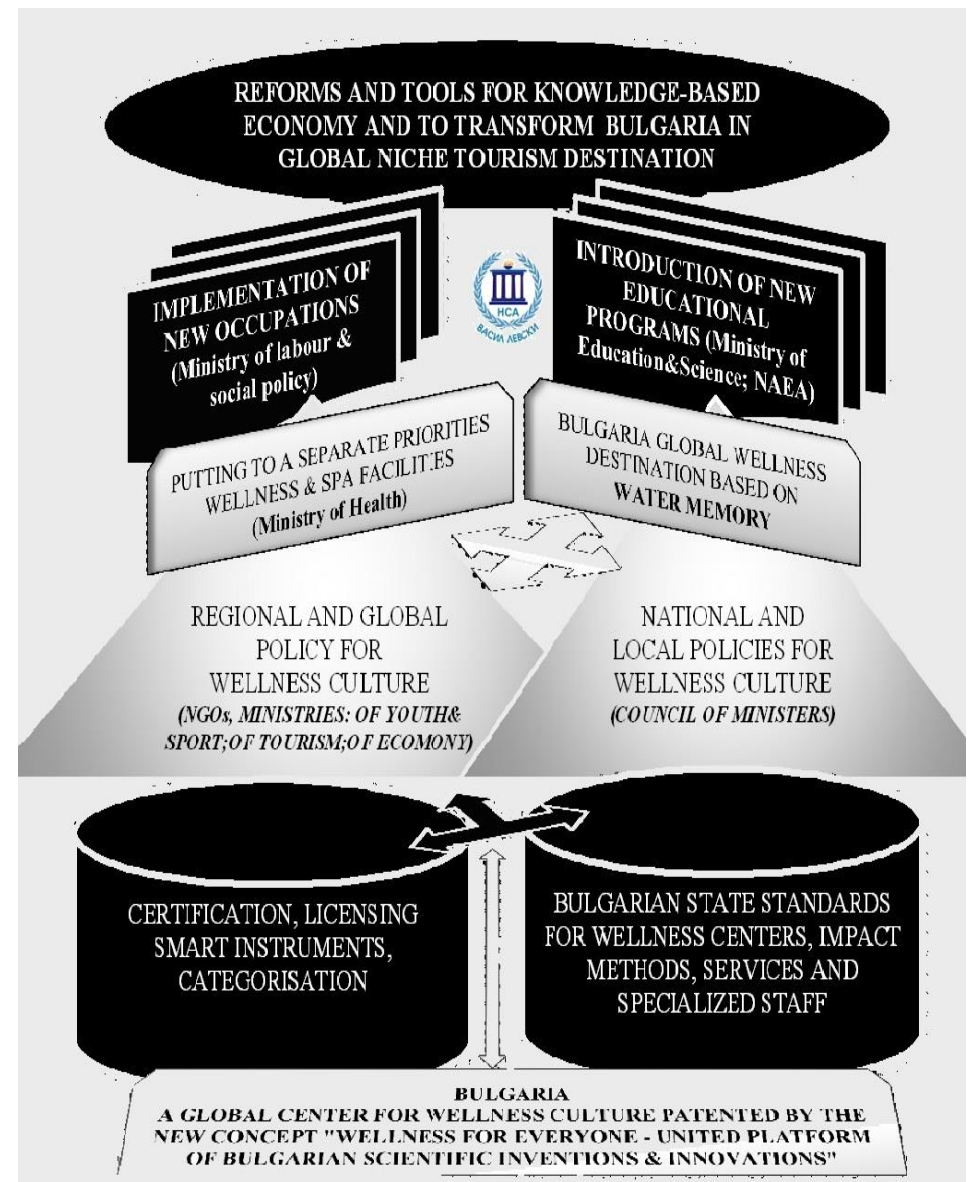

Figure 3. The succession of decisions, actions, and reforms for the transformation of Bulgaria into a global centre for Recreation industry.

The benefits for the development of the centre for Excellence: Heritage BG is to encourage other interested individuals in the sector to use and manage the experimental results in the best way possible. This central role is to inspiring business to finance scientific researches and innovations to maximise the impact of scientific investigations in favour of the citizens. Notable social importance for the development of the direct connection between the business and science is that scientific results can be used directly in practice and/or play an active role with guaranteed effectiveness for the interested parties which can receive high income from the incorporated innovations. The creation and development of the Center for Excellence: Heritage $\mathrm{BG}$ aims to showcase the broader socioeconomic benefits of the investment of the government and EU in the scientific research and innovations. The new scientific models fit cumulative criteria which clearly define the social benefits from the experimental results in support of citizens health prevention. The young scientists need to be trained to use results from their scientific studies and innovations and directly benefit the knowledge-based economy or to have played an active role in the perceptions of the results by third parties for the creation of inclusive intellectual growth. The direct and indirect exploitation of the consequences might be studied through various forms that can show and effect over the change in politics, commercialisation of the service or product, the creation of a startup/innovation business, and/or the creation of a new standard, etc. The scientific results in the Bulgarian Center for Excellence: Heritage BG (CoExc.) are expected to be beneficial and to be directed towards the current needs of the recreation industry and niche tourism on a national, regional (Balkan), and European level. Scientists predict a long-term effect over the society, economics, politics, and strategies for niche tourism. An essential work criterion for one Center of Excellence. is to showcase how to absorb the scientific results, researches help for the solving of the social challenges generating economic, social, health, and political impact. When applying for the project, we presented a letter of support from the highest customer network - United Nations World tourism organisation, which highlights the importance of scientific researches and how their usage creates specific benefits for the quality of the end product and services in the niche tourism. In the consortium of the projects, there are eight research institutes, and four universities which 
join their power and expertise and the number of experts exceeds 230 people (young, independent, and leading scientists - 22 from NSA "V. Levski").

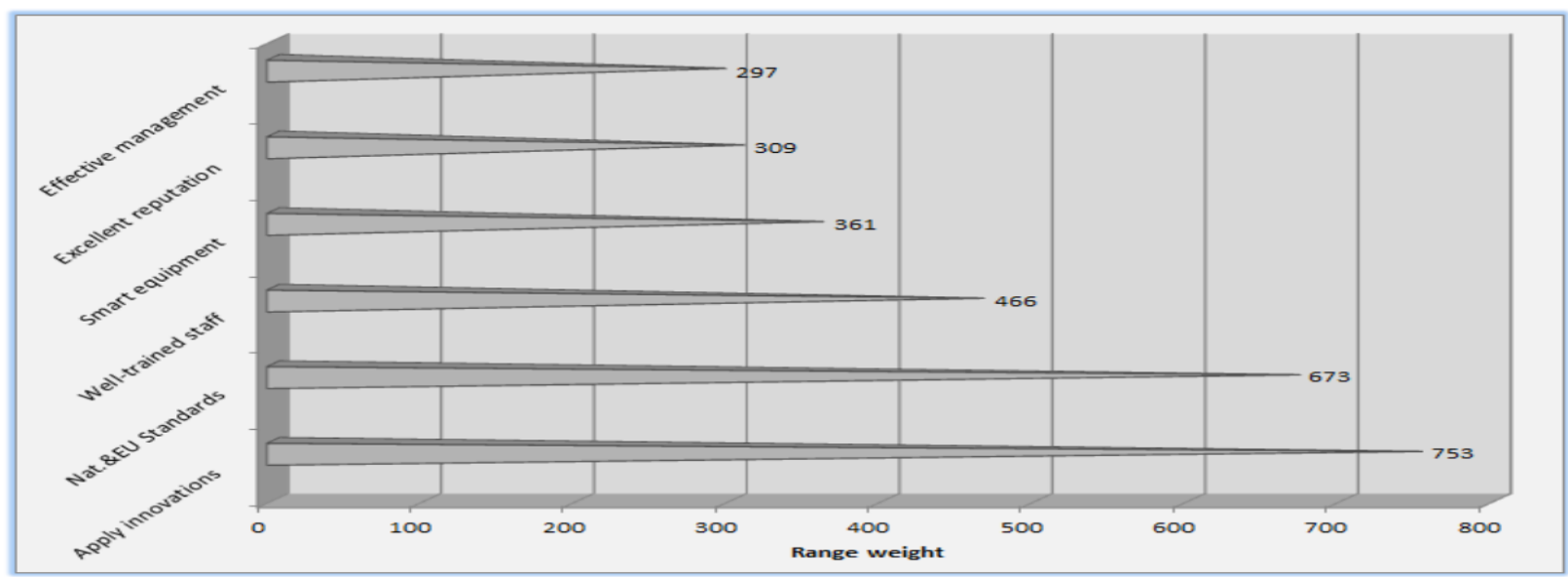

Figure 4. Expert ranking of indicators considering the requirements of efficiency services in the recreation centre

The results from the assessment for the significance of the indicators (Figure 4) are as follows: on first place is "the centre need to applies innovations in support of the costumers' wellbeing" (Weight 753 units $-88 \%$ ) and the centre needs to comply with the standards of quality of the services by the Wellness \& SPA National and EU standards (rank with the weight of 673 units- 63\%). Place 3rd and 4th are taken by the "Well-trained staff "(rank with a weight of 466 units- 68, 5\%) and every center needs Smart equipment to deliver effective services (grade with a weight of 361 units- 44.5\%). Indicators: "the centre needs to have an excellent public reputation" to be competitive and "the centre needs to have an effective management structure" are covered by rank with a weight of 309 units $(71.5 \%)$ and grade with a weight of 297 units $(64.5 \%)$. The arrangement of the other researched indicators (7-9 place) are as follows: optimum price strategy and promotional packages; a large variety of wellness and antiageing services; flexible marketing politics; favourable and clean work conditions and career development of the employees. We present the results from the study of respondents' views for the new Smart test usage (Table 1).

Table 1. Results found by the assessment of respondents' views for the Smart App test on Wellness culture knowledge.

\begin{tabular}{|c|c|c|c|c|c|c|c|c|}
\hline \multirow{2}{*}{\begin{tabular}{|l|}
\multicolumn{1}{|c|}{ Indicators } \\
\\
$\begin{array}{l}\text { The online test makes the } \\
\text { assessment of knowledge about } \\
\text { Wellness culture transparent }\end{array}$
\end{tabular}} & \multicolumn{2}{|c|}{$\begin{array}{l}\text { B.1 } \\
\text { (Bachelor } \\
\text { students) }\end{array}$} & \multicolumn{2}{|c|}{$\begin{array}{c}\text { M.2 } \\
\text { (Master } \\
\text { students) }\end{array}$} & \multicolumn{2}{|c|}{$\begin{array}{c}\text { S.3 } \\
\text { (Scholars) }\end{array}$} & \multicolumn{2}{|c|}{$\begin{array}{c}\text { O.4 } \\
\text { (Owners \& } \\
\text { managers \& PhD) }\end{array}$} \\
\hline & 25 & $42 \%$ & 37 & $43 \%$ & 12 & $48 \%$ & 19 & $50 \%$ \\
\hline $\begin{array}{l}\text { The Online Test allows me to } \\
\text { refine my knowledge of } \\
\text { Wellness culture over my } \\
\text { mobile phone }\end{array}$ & 30 & $50 \%$ & 30 & $34 \%$ & 10 & $40 \%$ & 11 & $29 \%$ \\
\hline $\begin{array}{l}\text { The Online Test makes me } \\
\text { more confident in my } \\
\text { knowledge of Wellness culture }\end{array}$ & 10 & $17 \%$ & 17 & $20 \%$ & 3 & $12 \%$ & 8 & $21 \%$ \\
\hline I didn't have an opinion & 5 & $8 \%$ & 3 & $3 \%$ & 0 & $0 \%$ & 0 & $0 \%$ \\
\hline Total (210): & 60 & $100 \%$ & 87 & $100 \%$ & 25 & $100 \%$ & 38 & $100 \%$ \\
\hline
\end{tabular}

The half $(50 \%)$ of bachelors opinions give attention to the possibility to refine Wellness culture knowledge over their mobile phone (respectively $\quad 34 \% \quad$ Masters, 29\% Owners\&managers\&PhD and $40 \%$ Scholars). For the group of Owners\&managers\&PhD 
student the transparency during the assessment of knowledge is with high importance (respectively 43\% Masters, 42\% Bachelors and $48 \%$ Scholars).

\section{DISCUSSION}

In the research about the content of the intellectual products needed for training of the new professions"Wellness advisor" and "Wellness Instructor", in particular the Smart test for Wellness knowledge based on the preferences of most of the respondents $(50 \%)$ we established: based on the data analysis for the quality of the services, it was discovered that the highest importance is to apply innovative services, Smart equipment and the professional qualification of the personnel to ensuring the efficiency of the performance by the offered specific services. Respondents determined for priority metrics of the ranking the implementation of the united educational standards (in relation to the criteria of the EU and qualification frame). It is important that these standards for professional competencies are implemented by all public institutions, responsible for the national certification of personnel in the wellness sector and in particular the Niche tourism. Countries from our partner networks such as: Austria, Estonia, United Kingdom, Serbia, Romania, and Macedonia, also discovered with similar testing researches that there is an urgent need of specialized programs for training of specialists in the Niche tourism. The future professionals in the Recreation and Wellness industry need stable knowledge, professional and personal competencies about effective organizational and methodological approaches such as: knowledge, intellectual and practical skills for various procedures and health influences, based on the natural resources and holistic approaches. The high motivation about offering and delivering quality services adapted to the needs of the clients and healthy lifestyle and quality of life (wellness lifestyle) as well as encouraging the interest of the citizens for bettering of the national wellbeing index are very important for the services in the EU region. In this regard, it is necessary to activate all professional relations between academic units, centers for professional education and training, high schools, and professional educational institutions in order to build a bridge between theory and business practices in the recreation industry (with a real practice in a real professional environment). Under our scientific leadership, project Eramus
+ , KA2 "WELVET" (wellness instructor vocational education and training) develop educational program (for certification of competencies), academic distribution (by classes) as well as an analysis of the wellbeing index in 5 project partner countries. The latest program (under the CoExc. Heritage BG) "Wellness Advisor" on a bachelor degree is published in July 2019. The issued intellectual products are rated with a high significance for adding value to the educational and labour politics in the EU which are expected to secure intellectual growth. The 5 new Wellness \& Spa $\&$ Thalasso programs from Bachelor until doctoral degree in two professional majors were successfully accredited and highly valued by the experts in the Bulgarian agency evaluation and accreditation (NAEA): 7.5 health care and 7.6 sports. The presented innovative and stable educational and scientific model is incorporated in the National sports academy "V. Levski" which proves its position as an educational leader on a national, regional, and European level.

\section{CONCLUSIONS}

In conclusion, based on the conducted research, the following implications can be drawn:

1. On a European level, the recreation industry needs better trained professionals who have graduated in specialized programs for high school and university levels;

2. The Bulgarian model consists of 7 accredited programs for operational staff and managers for Wellness \& Spa \& Thalasso services and methodologies with a requirement for high skills acquired during their education and training;

3. In Europe and on the Balkans, in order to acquire a manager position in the recreation industry, a person needs interdisciplinary knowledge and skills combined with the application of wellness culture for motivating the citizens to adopt a healthier lifestyle;

4. Bulgaria has proven to have the potential to be a Balkan educational leader in the sector of Recreation industry and Niche tourism;

5. Europe adopts high standards and criteria for the quality of education and the professional competencies for specialized personnel in the recreation industry and niche tourism. 


\section{REFERENCES}

1. Dimitrova, B. New smart educational model Wellness instructor. First Edition, Avangrd Prima, Sofia, Bulgaria, p. 33-42, 2019.

2. Nesheva, I. Research impact through scientific reports in international forum. Summary case Studies. First EdItion, Avangard Prima, Sofia, Bulgaria, p 34-35, 2016.

3. Dimitrova, B. et al. Multilingual app content for Android and iPhone presenting the "wellness instructor" VET course standard. First EdItion, Avangrd Prima, Sofia, p. 2329, 2018.

4. Ellis, S. The global wellness tourism economy Report. Global Wellness Tourism Congress (Delhi, India). GWI, Miami, USA, p. 9-10, 2013.

5. Global Wellness Institute Economic Report. GWI, Miami, USA, p. 27-28, 2014. Available at: https://www.globalwellnessinstitute.org

6. Ellis, S. The global wellness tourism economy Report. Global Wellness Tourism Congress (Delhi, India). GWI, Miami, USA, p. 9-10, 2013.

7. Polimenov, M., Inovation in SPA and enology as opportunity to raise the Competitiveness of tourist services. Paper presented at the Intrenational tourist forum Spa and wine. South-West University "Neophyte Rilski". Proceedings, Blagoevgrad, Bulgaria, p. 163, 2014.

8. Dimitrova, B. Inteligentni kompetentsii za nishov turizŭm. Ed. Avangrd Prima, Sofia, Bulgaria, p. 33-42, 2019, (In Bulgarian)

9. Valev Y. Usǔvŭrshenstvane na podgotovkata na ezdacha i konya po preskachane na prepyat·stviya, Ed. NSA Pres, Sofia, Bulgaria, p. 29-56, 2018, (In Bulgarian)

10. Government Office for Science. Foresight mental capital and wellbeing project. Final project report. London. Mental Capital and Wellbeing: Making the most of ourselves in the 21st century, p.10-11, 2008. Available at: https://assets.publishing.service.gov.uk/ government/uploads/system/uploads/ attachment_data/file/292453/mental-capitalwellbeing-summary.pdf (Accessed 13 Dec 2017).

11.Stiglitz, J. E., Sen, A., \& Fitoussi, J. P. Report by the commission on the measurement of economic performance and social progress, p.16-17, 2009 . Available at: http://www.stiglitz-sen- fitoussi.fr/documents/rapport_ anglais.pdf. (Accessed 28 Sept 2012).

12. Layard, R. Happiness: Lessons from a new science. L.: Penguin, 8. p.8-9, 2005, Google Scholar.

13. Sachs, J. Sustainable Development Goals (SDGs). Sustainable development is a holistic approach to well-being. Paper presented to heads of state at a special summit at the United Nations, in September 2015. The 70th anniversary of the UN, New York, 2015. Available at: www.globalwellnessinstitute.com

14. Cavanah, C. Guide to Hydrothermal Spa \& Wellness Development Standards. Global Wellness Institute Press, Miami, USA, p. 3233, 2016.

15. Trendafilov, D., B. Dimitrova. Aqua Spinning as anti-stress health prevention. Sport Mont, Vol. XI (37-38-39), p. 467-473, 2013.

16. Nesheva, I. Benefits of the physical activity and the elaborated program mental prevention gym for women with normal pregnancy. Research in Kinesiology, Vol. 43(2), p. 212213, 2015.

17. Dimitrova, B. et al. Social Impact of Wellness (Wellness) culture. Comparative analysis from Gallup international research data for global well-being Index. Avangard Prima, p.11-13, Sofia, Bulgaria, 2018.

18. Doncheva, L. \& Dimitrova, L Innovative Way of Teaching English in Class and Its Influence on Pupils' Level of Concentration. Paper presented at the Vth Congreso de Internacional de Competencias Básicas, 1315 de Abril 2016: la competencia en comunicación lingüística, Ciudad Real, p. 2122, 2016.

19. Dimitrova, B. Magistŭrska programa po SPA kultura, hidro, lito i talaso praktiki, s prodŭlzhitelnost 2 godini [Master's Program in SPA culture, hydro, lytho and thalasso practices, with two years duration]. Avangard Prima, Sofia, p. 7-11, 2014. (In Bulgarian)

20. Dimitrova, B. et al. Multilingual app content for Android and iPhone presenting the "wellness instructor" VET course standard. First EdItion, Avangrd Prima, Sofia, p. 2329, 2018.

21. Harizanova, O. New scientific infrastructure for innovations on the creative and recreation industries. Smart innovations in the Recreation \& Wellness Industry and Niche Tourism Journal, (1), p.17-21, 2019. 